\title{
Root Canal Disinfection Using Highly Effective Aggregation-Induced Emission Photosensitizer
}

Xuewen Zhang, ${ }^{\dagger, \#}$ Yao Chen, ${ }^{\dagger, \#}$ Cong Li, ${ }^{\dagger}$ Zhijun Xue,,$^{\dagger}$ Hongshan Wu, ${ }^{\dagger}$ Jun Li,,+ Hanlin Ou,,+

Jing Shen, ${ }^{*} \dot{\dagger}$ and Dan Ding ${ }^{*,+, t}$

†Tianjin Key Laboratory of Oral and Maxillofacial Function Reconstruction, Tianjin

Stomatological Hospital, The Affiliated Stomatological Hospital of Nankai University,

Tianjin 300041, China

Key Laboratory of Bioactive Materials, Ministry of Education, and College of Life Sciences,

Nankai University, Tianjin 300071, P. R. China

*Address correspondence to dingd@nankai.edu.cn (D. Ding), shenjing611@163.com (J.

Shen). 


\section{Supplementary figures and tables}

Table S1. Midian (Minimum-Maximum). Percentage of survival bacteria after treatment of each group. Kruskal-Wallis test $(P<0.05)$. Different capital letters represent significant differences among the groups.

\begin{tabular}{|c|c|c|c|}
\hline Control & DPA-SCP & Light & DPA-SCP+Light \\
\hline $80.0(65.0-101.3)^{\mathrm{A}}$ & $84.4(70.0-98.8)^{\mathrm{A}}$ & $76.9(67.5-88.8)$ & $3.7(2.3-5.1) \times 10^{-4}$ \\
\hline
\end{tabular}

Table S2. Midian (Minimum-Maximum). Percentage of survival bacteria after treatment of different DPA-SCP concentrations. Kruskal-Wallis test followed by Nemenyi test. Different capital letters represent significant differences among the groups $(P<0.05)$.

\begin{tabular}{|c|c|c|c|c|c|c|c|}
\hline Control & $10 \mu \mathrm{g} / \mathrm{ml}$ & $25 \mu \mathrm{g} / \mathrm{ml}$ & $40 \mu \mathrm{g} / \mathrm{ml}$ & $50 \mu \mathrm{g} / \mathrm{ml}$ & $60 \mu \mathrm{g} / \mathrm{ml}$ & $75 \mu \mathrm{g} / \mathrm{ml}$ & $100 \mu \mathrm{g} / \mathrm{ml}$ \\
\hline $\begin{array}{c}85.1 \\
(40.0-100.0)^{A}\end{array}$ & $\begin{array}{c}0.19 \\
(0.11-0.21)^{\mathrm{AB}}\end{array}$ & $\begin{array}{c}0.78 \\
(0.38-1) \times 10^{-3^{B}}\end{array}$ & $\begin{array}{c}0.88 \\
(0.43-1.38) \times 10^{-3^{B}}\end{array}$ & $\begin{array}{c}0.38 \\
(0-2.5) \times 10^{-6^{C}}\end{array}$ & $\begin{array}{c}0.13 \\
(0-1.04) \times 10^{-6^{c}}\end{array}$ & $\begin{array}{c}0.13 \\
(0-1.04) \times 10^{-6}\end{array}$ & $\begin{array}{c}0.13 \\
(0-1.04) \times 10^{-6}\end{array}$ \\
\hline
\end{tabular}

Table S3. Midian (Minimum-Maximum). Percentage of survival bacteria after treatment of different light power. Kruskal-Wallis test followed by Nemenyi test. Different capital letters represent significant differences among the groups $(P<0.05)$.

\begin{tabular}{|c|c|c|c|c|}
\hline Control & $0.02 \mathrm{w} / \mathrm{cm}^{2}$ & $0.2 \mathrm{w} / \mathrm{cm}^{2}$ & $0.8 \mathrm{w} / \mathrm{cm}^{2}$ & $2.0 \mathrm{w} / \mathrm{cm}^{2}$ \\
\hline $77.8(47.5-87.5)^{\mathrm{A}}$ & $45.8(12.5-50.0)^{\mathrm{AB}}$ & $14.6(8.8-16.3)^{\text {B }}$ & $0.087(0.05-0.10)^{\mathrm{BC}}$ & $0.13(0-0.38) \times 10^{-6^{c}}$ \\
\hline
\end{tabular}

Table S4. Midian (Minimum-Maximum). Percentage of survival bacteria after treatment of different DPA-SCP incubation time. Kruskal-Wallis test followed by Nemenyi test. Different capital letters represent significant differences among the groups $(P<0.05)$.

\begin{tabular}{|c|c|c|c|c|c|c|}
\hline Control & $\mathbf{O h}$ & $0.5 \mathrm{~h}$ & $1 \mathrm{~h}$ & $1.5 \mathrm{~h}$ & $2 \mathrm{~h}$ & $2.5 \mathrm{~h}$ \\
\hline $\begin{array}{c}80.0 \\
(60.0-100.0)^{\mathrm{A}}\end{array}$ & $\begin{array}{c}0.068 \\
(0.051-0.1)\end{array}$ & $\begin{array}{c}0.0245 \\
(0.015-0.034)^{\text {В }}\end{array}$ & $\begin{array}{c}0.0195 \\
(0.013-0.06)\end{array}$ & $\begin{array}{c}0.79 \\
(0.43-2.5) \times 10^{-3}{ }^{\mathrm{BC}}\end{array}$ & $\begin{array}{c}0.155 \\
(0.1-0.3) \times 10^{-3} \mathrm{C}\end{array}$ & $\begin{array}{c}0.335 \\
(0.2-0.8) \times 10^{-3}{ }^{C}\end{array}$ \\
\hline
\end{tabular}


Table S5. Midian (Minimum-Maximum). Percentage of survival bacteria after treatment of different light irradiation time. Kruskal-Wallis test followed by Nemenyi test. Different capital letters represent significant differences among the groups $(P<0.05)$.

\begin{tabular}{cccc}
\hline Control & $\mathbf{5}$ min & $\mathbf{1 0 ~}$ min & 15 min \\
\hline $81.3(73.8-93.8)^{\mathrm{A}}$ & $2.2(1.4-3.1)^{\mathrm{AB}}$ & $4.9(3.1-6.8) \times 10^{-4^{\mathrm{B}}}$ & $2.5(0-7.5) \times 10^{-5^{\mathrm{C}}}$ \\
\hline
\end{tabular}

Table S6. Median (Minimum-Maximum). Percentage of survival bacteria in the dentinal tubes after treatment of each group. Kruskal-Wallis test followed by Nemenyi test. Different capital letters represent significant differences among the groups $(P<0.05)$.

\begin{tabular}{|c|c|c|}
\hline Control & PDT & $\mathrm{NaClO}$ \\
\hline $101(81-117)^{\mathrm{A}}$ & $0.072(0.06-0.08)^{\mathrm{B}}$ & $0.051 \quad(0.02-0.07)$ \\
\hline
\end{tabular}

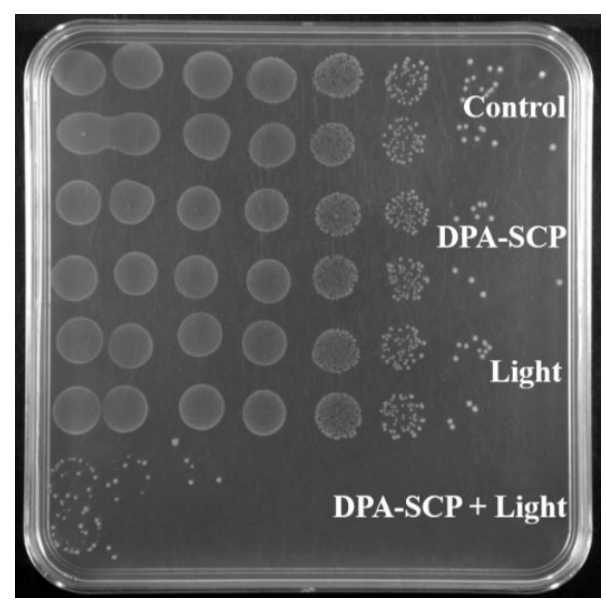

Figure S1. Antibacterial results. Agar plates sprayed of E. faecalis with different treatment. 


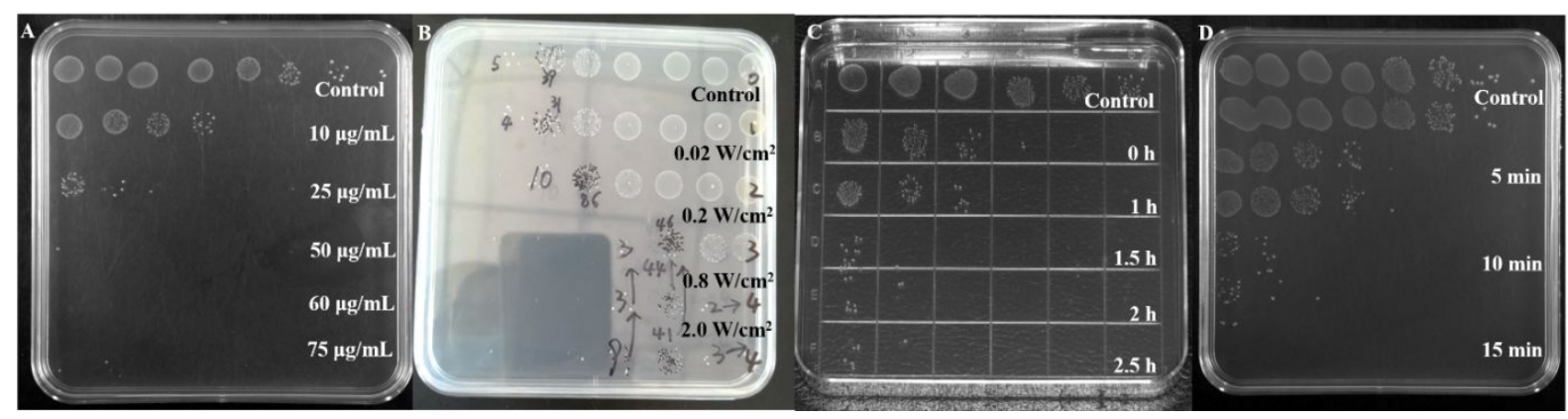

Figure S2. Antibacterial results. Agar plates sprayed of E. faecalis with different concentrations of DPA-SCP (A), light power (B), DPA-SCP incubation time (C) and light irradiation time (D).

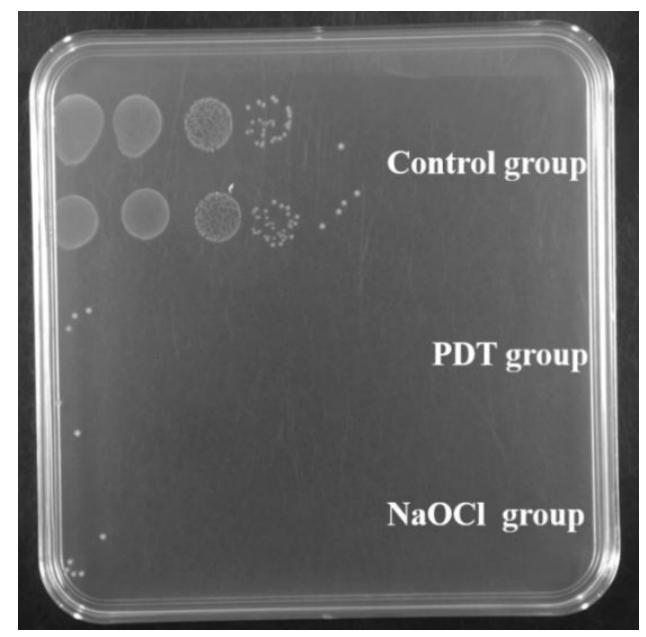

Figure S3. Antibacterial results. Agar plates sprayed of E. faecalis with different treatment.

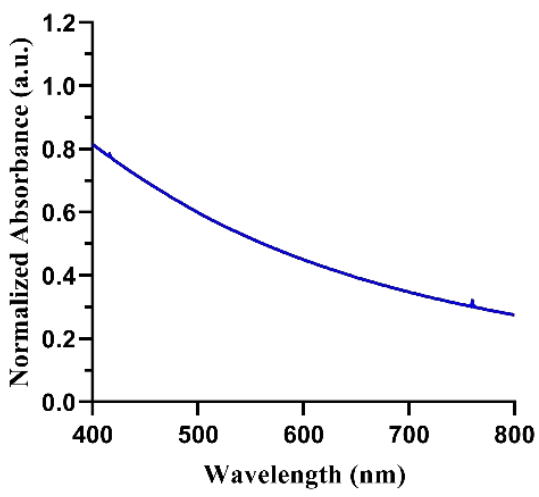

Figure S4. UV-vis absorption spectrum of E. faecalis itself. 